\title{
Validation of population-based cut-offs for low muscle mass and strength
}

\author{
Pinar Soysal ${ }^{1} \cdot$ Lee Smith $^{2} \cdot$ Ahmet Turan Isik ${ }^{3}$ \\ Published online: 8 June 2020 \\ (c) European Geriatric Medicine Society 2020
}

Keywords Muscle mass $\cdot$ Muscle strength $\cdot$ Cut-off

With prolonged life expectancy, existing comorbid diseases have become insufficient to evaluate the health status of older adults. The conceptual occurrence of geriatric syndromes specific to old age has now emerged [1]. Although dementia, incontinence, polypharmacy, falls, malnutrition have been studied for many years, some geriatric syndromes have only been discussed over the past few decades [1]. One example is sarcopenia, characterized by progressive muscle strength and decrease in mass, which eventually results in functional decline, physical disabilities, falls, fractures, poor quality of life, frequent hospitalizations and mortality. Thus early diagnosis is critical to prevent these adverse outcomes [2].

Since it is a new geriatric syndrome, the definition and criteria of sarcopenia have changed recently [3]. In 2010, The European Working Group on Sarcopenia in Older People (EWGSOP) suggested that the presence of both low muscle mass (MM) and low muscle function (strength or performance) for its diagnosis [4]. However, these guidelines were revised in 2019 by the EWGSOP2, wherein muscle strength (MS) was considered as strength and is a better predictor of adverse outcomes than MM [3]. Moreover, the uncertainty in diagnosis is not limited to whether MM or MS should be prioritized in the algorithm. Gender and ethnic differences have forced different geographical regions to determine their

Pinar Soysal

psoysal@bezmialem.edu.tr

1 Department of Geriatric Medicine, Bezmialem Vakif University, Faculty of Medicine, Adnan Menderes Bulvarı, Vatan Caddesi, 34093 Fatih/İstanbul, Turkey

2 The Cambridge Centre for Sport and Exercise Science, Anglia Ruskin University, Cambridge, UK

3 Unit for Aging Brain and Dementia, Department of Geriatric Medicine, Dokuz Eylul University, Faculty of Medicine, Izmir, Turkey own cut-off values for sarcopenia. In a study published in the last issue of the European Geriatric Medicine Journal, it was aimed to determine cut-offs for low MS and low MM and find out the prevalence of sarcopenia in Indians [5]. The study by Pal et al. found that handgrip strength $<27.5 \mathrm{~kg}$ (males) $/ 18.0 \mathrm{~kg}$ (females) and appendicular skeletal muscle index $<6.11 \mathrm{~kg} / \mathrm{m}^{2}$ (males) $/ 4.61 \mathrm{~kg} / \mathrm{m}^{2}$ (females) defined low MS and MM, respectively. The study has demonstrated that MM is lower in Indians compared to EWGSOP criteria; hence, applying Western cut-offs leads to overestimation of sarcopenia in the Indian context. Similarly, in the study of Ates Bulut et al., a cut-off assessment specific to Turkish society was aimed for MM and MS, and MM cut-off values were calculated as $5.70 \mathrm{~kg} / \mathrm{m}^{2}$ for women and $8.33 \mathrm{~kg} / \mathrm{m}^{2}$ for men, and MS thresholds were calculated as $14 \mathrm{~kg}$ for women and $28 \mathrm{~kg}$ for men [6]. Although Turkey is one of the European countries, similar to India population, the cut-off values were found to be lower in accordance with revised EWGSOP criteria.

In conclusion, the evaluation of sarcopenia according to the present guidelines may cause overdiagnosis in some populations. Due to the anthropometric differences between societies, large-scale observational studies to be conducted in different countries of the world will show whether it is correct to offer guidelines containing threshold values at the continent level for MM and MS.

Author contributions All authors have seen and approved the manuscript.

Funding None. 


\section{Compliance with ethical standards}

Conflict of interest All authors declare that they have no conflict of interest.

\section{References}

1. Ates Bulut E, Soysal P, Isik AT (2018) Frequency and coincidence of geriatric syndromes according to age groups: single-center experience in Turkey between 2013 and 2017. Clin Interv Aging 13:1899-1905

2. Beaudart C, Zaaria M, Pasleau F, Reginster J-Y, Bruyere O (2017) Health-outcomes of sarcopenia: a systematic review and meta analysis. PLoS ONE 12(1):e0169548

3. Cruz-Jentoft AJ, Bahat G, Bauer J, Boirie Y, Bruyere O, Cederholm T et al (2019) Sarcopenia: revised European consensus on definition and diagnosis. Age Ageing 48(1):16-31

4. Cruz-Jentoft AJ, Baeyens JP, Bauer JM, Boirie Y, Cederholm T, Landi F et al (2010) Sarcopenia: European consensus on definition and diagnosis: report of the European Working Group on sarcopenia in older people. Age Ageing [Internet] 39(4):412-423. https ://www.ncbi.nlm.nih.gov/pubmed/20392703\%5Cn. https://www. pubmedcentral.nih.gov/articlerender.fcgi?artid=PMC2886201

5. Pal R, Aggarwal A, Singh T, Sharma NS, Khandelwal AG, Bhansali A, Kumar A, Yadav U, Singh P, Dhiman V, Pinaki Dutta SKB (2020) European geriatric medicine. Eur Geriatr Med. https ://doi.org/10.1007/s41999-020-00332-z

6. Ates Bulut E, Soysal P, Dokuzlar O, Kocyigit SE, Aydin AE, Yavuz I et al (2020) Validation of population-based cutoffs for low muscle mass and strength in a population of Turkish elderly adults. Aging Clin Exp Res. https://doi.org/10.1007/s40520-019$01448-4$

Publisher's Note Springer Nature remains neutral with regard to jurisdictional claims in published maps and institutional affiliations. 